\title{
BMJ Open Association between neck circumference and cardiometabolic disease in Chinese adults: a community-based cross- sectional study
}

\author{
Wenning Fu, ${ }^{1,2}$ Li Zou, ${ }^{3}$ Xiaoxu Yin, ${ }^{1}$ Jiang Wu, ${ }^{4}$ Shengchao Zhang, ${ }^{4}$ Jing Mao, ${ }^{2}$ \\ Shiyi Cao, ${ }^{1}$ Wenzhen Li, ${ }^{1}$ Yong Gan, ${ }^{1}$ Shijiao Yan, ${ }^{5,6}$ Yanhong Gong, ${ }^{1}$ Zuxun Lu ${ }^{1}$
}

To cite: Fu W, Zou L, Yin X, et al. Association between neck circumference and cardiometabolic disease in Chinese adults: a community-based crosssectional study. BMJ Open 2019;9:e026253. doi:10.1136/ bmjopen-2018-026253

- Prepublication history and additional material for this paper are available online. To view these files, please visit the journal online (http://dx.doi. org/10.1136/bmjopen-2018026253).

Received 25 August 2018 Revised 25 September 2019 Accepted 16 0ctober 2019

Check for updates

(C) Author(s) (or their employer(s)) 2019. Re-use permitted under CC BY-NC. No commercial re-use. See rights and permissions. Published by BMJ.

For numbered affiliations see end of article.

Correspondence to

Professor Zuxun Lu;

zuxunlu@yahoo.com

\section{ABSTRACT}

Objectives Several studies have indicated that neck circumference (NC) was associated with cardiometabolic disease in some Western countries. However, there are limited data regarding this association among Chinese adults.

Design A community-based cross-sectional study. Setting A multistage-stratified random cluster survey was conducted in Xixiang Street, Bao'an District of Shenzhen in southeast China.

Participants This study included 4000 participants (1605 men and 2395 women) with a mean age of $56.0 \pm 9.8$ years.

Main outcome measures Categorical data were reported as percentage and continuous data were reported as mean $\pm S D$. Receiver operating characteristic analysis and logistic regression analysis were used to evaluate the association of NC with cardiometabolic disease.

Results The mean NC values were $35.50 \pm 4.23 \mathrm{~cm}$ for men and $32.32 \pm 3.59 \mathrm{~cm}$ for women. After adjusting for body mass index and waist circumference, NC was significantly associated with the risk of hypertension (OR: 1.42 in women), decreased high-density lipoprotein (HDL) levels (OR: 1.27 in men; OR: 1.12 in women), high triglyceride (TG) levels (OR: 1.54 in women) and diabetes (OR: 1.41 in men; OR: 1.37 in women). Among men, the optimal NC cut-off values were $38.10 \mathrm{~cm}$ for identifying hypertension, $32.32 \mathrm{~cm}$ for decreased HDL levels, 36.6 $\mathrm{cm}$ for high TG levels and $36.6 \mathrm{~cm}$ for diabetes. Among women, the optimal NC cut-off values were $32.35 \mathrm{~cm}$ for identifying hypertension, $33.40 \mathrm{~cm}$ for decreased $\mathrm{HDL}$ levels, $32.90 \mathrm{~cm}$ for high TG levels and $33.40 \mathrm{~cm}$ for diabetes.

Conclusions NC was significantly associated with cardiometabolic disease in Chinese population. Although further studies are needed to confirm the optimal cutoff values, evaluating NC may be useful for predicting cardiometabolic disease risk during clinical assessments.

\section{INTRODUCTION}

Cardiometabolic disease such as diabetes, dyslipidaemia and cardiovascular disease ${ }^{12}$ are the common condition seen in primary care, which have increased substantially in recent years, and imposed heavy burden on

\section{Strengths and limitations of this study}

- This is the first study to explore optimal neck circumference cut-off values for discriminating diabetes and dyslipidaemia in this population.

- The present study is limited by its cross-sectional design, which precludes interpretation of the causality of the associations that were observed. Another limitation is that the participants were middle-aged and older Chinese adults, although similar results have been observed among younger subjects.

- Due to developing and validating using the same dataset, further population-based studies are needed to validate the diagnostic utility.

healthcare systems. Cardiometabolic disease is estimated to be responsible for a substantial proportion of morbidity and premature mortality globally. ${ }^{3-6}$ The causes of cardiometabolic disease are complex and correlated with numerous factors, with obesity being an established risk factor. ${ }^{7-10}$ Total body obesity and visceral obesity can be evaluated based on body mass index (BMI), waist circumference (WC) and waist-to-hip, which may predict the risk of cardiometabolic disease. ${ }^{11-14}$ However, recent studies have suggested upper-body subcutaneous adipose tissue, as estimated by neck circumference (NC) is more pathogenic than total body obesity and abdominal visceral fat. $^{1015}$

$\mathrm{NC}$ measured at the inferior margin of the laryngeal prominence was a better indicator of obesity than the other anthropometric indexes, ${ }^{16}$ as it is a clear and convenient measurement at an explicit anatomical landmark that exhibits minimal fluctuations that are related to diet or respiratory conditions. Therefore, NC is a convenient tool for use in clinical settings, especially in primary healthcare institutions. 
Recent studies have also indicated that NC was associated with hypertension, diabetes, metabolic syndrome and dyslipidaemia, which includes high total cholesterol (TC) levels, high triglyceride (TG) levels, high lowdensity lipoprotein cholesterol (LDL-C) levels and low high-density lipoprotein cholesterol (HDL-C) levels. ${ }^{15} 17$ However, there are limited data regarding these associations among Chinese adults, and the existing studies have mainly focused on the relationship between NC and hypertension. ${ }^{17-20}$ Furthermore, some studies have used receiver operating characteristic (ROC) analysis to evaluate the accuracy of $\mathrm{NC}$ as diagnostic tests for cardiometabolic disease, and indicated that NC may be a valuable anthropometric index to predict cardiometabolic disease risk, ${ }^{162122}$ although similar researches in China are scarce and no studies have identified the optimal cut-off values for predicting diabetes and dyslipidaemia in the Chinese population. Moreover, there are significant differences in the genetic backgrounds and criteria for obesity in the Asian and Western populations. China is the most populous nation in the world (with one-fifth of the world's population), similar researches in China are scarce and no studies have identified the optimal cut-off values for predicting diabetes and dyslipidaemia in the Chinese population. Therefore, the present study aimed to evaluate the relationship between $\mathrm{NC}$ and cardiometabolic disease among Chinese adults, and to establish NC cut-off values for predicting specific cardiometabolic diseases in the Chinese population.

\section{METHODS}

\section{Patient and public involvement}

This cross-sectional survey was conducted in the Bao'an District of Shenzhen (southeast China) between January 2015 and March 2016. Xixiang Street had 33 communities. TaoyuanJu, Liutang, Xixiang were selected in our study which should meet the following eligibility criteria: (1) the medical staff working in the community health service centre was proactive in engagement with the health education programme; (2) a well-maintained health record was provided and (3) it was located in either the national exemplary area of comprehensive prevention and control of chronic diseases or the national monitoring spot of chronic diseases. Subsequently, a multistage-stratified cluster survey was conducted on a random basis for each community. During the first-stage sampling, a computer program was applied to choose totally 4202 households at random among the three selected communities with the following requirements: (1) participants were required of a permanent residence for a minimum of 6 months annually in the community to ensure they could be contact and the age was restricted to 40 and over and (2) participants with mental disorder were prohibited from participation and the consent to survey participation was expressed. At the second-stage sampling, a random selection of suitable participants was conducted among each household that had been contacted for engagement with the interview.
Finally, all eligible participants were registered at the local government and informed to do laboratory examinations in community health centres at a specific time.

\section{Data collection}

A total of 4238 participants (1730 men and 2508 women) were recruited to undergo NC measurements, blood testing and a physical examination. In addition, participants completed a questionnaire regarding their age, sex, socioeconomic status, smoking, alcohol consumption habits and disease history. The physical examination included measurements of height, weight, NC and WC. Blood samples were obtained after an overnight fast to examine the participants' biochemical characteristics. Individuals were excluded if they had diagnosed illnesses, such as thyroid diseases, neck masses and deformities or malignant diseases. In addition, we excluded participants with implausible values for BMI $\left(<15 \mathrm{~kg} / \mathrm{m}^{2}\right.$ and $>50 \mathrm{~kg} / \mathrm{m}^{2}$ ) and blood pressure (systolic blood pressure $(\mathrm{SBP}):<80$ or $>250 \mathrm{~mm} \mathrm{Hg}$, diastolic blood pressure (DBP): $<40$ or $>150 \mathrm{~mm} \mathrm{Hg}$ ). Based on these exclusions, 4000 participants were included in the analyses.

\section{Anthropometric and biomarker measurements}

Each participant's horizontal NC was measured with their head erect and eyes facing forward, at the upper margin of the laryngeal prominence. Height without shoes was measured to the nearest $0.1 \mathrm{~cm}$ using a portable stadiometer. Weight in light clothing was measured to the nearest $0.1 \mathrm{~kg}$ using a digital scale. Each participant's WC was measured to the nearest $0.1 \mathrm{~cm}$ at the midpoint between the iliac crest and the lower rib.

All participants provided blood samples after a $>8$ hour overnight fast, which were collected into glass tubes and allowed to clot at room temperature. An enzymatic calorimetric test was used to measure the levels of TC, TG, LDL-C, HDL-C, fasting plasma glucose (FPG) and 2-hour post-load plasma glucose (2hPG) at a local hospital.

\section{Blood pressure measurements and assessment of cardiometabolic disease}

Blood pressure was measured after the participants had rested in a chair with back support for $10 \mathrm{~min}$. Both feet were placed flat on the floor and the arms were supported at heart level while a trained nurse measured the blood pressure using an automated sphygmomanometer. Three measurements were taken at 5 min intervals during 08:00-09:00, and the mean value was recorded for the analyses. Participants were instructed to refrain from drinking alcohol, tea or coffee, smoking, or exercising for $\geq 30$ min before the evaluation.

Hypertension was defined as SBP $\geq 140 \mathrm{~mm} \mathrm{Hg}$, DBP $\geq 90 \mathrm{~mm} \mathrm{Hg}$ or the current use of antihypertensive medication. ${ }^{23}$ Diabetes was defined as an FPG value $\geq 7.0$ $\mathrm{mmol} / \mathrm{L}$, a $2 \mathrm{hPG}$ value $\geq 11.1 \mathrm{mmol} / \mathrm{L}$ or current treatment using insulin or other hypoglycaemic agents. ${ }^{5}$ High TC was defined as a TC $\geq 6.22 \mathrm{mmol} / \mathrm{L}$, high TG was defined as a measurement of $2.26 \mathrm{mmol} / \mathrm{L}$ or higher, 
Table 1 Characteristics of the study participants stratified by gender

\begin{tabular}{|c|c|c|}
\hline Variable & Men $(n=1605)$ & Women $(n=2395)$ \\
\hline Age (years) & $56.02 \pm 10.15$ & $55.95 \pm 9.53$ \\
\hline BMI & $24.53 \pm 3.07$ & $24.06 \pm 3.48$ \\
\hline WC & $85.46 \pm 9.10$ & $80.42 \pm 9.81$ \\
\hline $\mathrm{NC}$ & $35.50 \pm 4.23$ & $32.32 \pm 3.59$ \\
\hline SBP & $128.03 \pm 17.31$ & $124.90 \pm 19.13$ \\
\hline DBP & $84.66 \pm 11.74$ & $80.37 \pm 11.09$ \\
\hline FPG & $5.97 \pm 10.02$ & $5.60 \pm 1.44$ \\
\hline TG & $1.85 \pm 1.49$ & $1.62 \pm 1.25$ \\
\hline TC & $4.81 \pm 0.96$ & $4.97 \pm 1.37$ \\
\hline LDL-C & $3.65 \pm 1.21$ & $3.49 \pm 1.15$ \\
\hline HDL-C & $0.89 \pm 0.75$ & $0.91 \pm 0.48$ \\
\hline $2 \mathrm{hPG}$ & $8.22 \pm 3.56$ & $8.31 \pm 3.23$ \\
\hline \multicolumn{3}{|l|}{ Education } \\
\hline Primary school & 327 (20.4) & $1004(42.0)$ \\
\hline Junior high school & $502(31.3)$ & $704(29.4)$ \\
\hline High school & $437(27.1)$ & $473(19.7)$ \\
\hline Junior College & $333(20.7)$ & $212(8.8)$ \\
\hline Master degree & $6(0.4)$ & $2(0.08)$ \\
\hline \multicolumn{3}{|l|}{ Smoking } \\
\hline No & $1030(64.2)$ & $2364(98.7)$ \\
\hline Yes & $575(35.8)$ & $31(1.3)$ \\
\hline \multicolumn{3}{|l|}{ Drinking } \\
\hline No & $1107(69.0)$ & $2302(96.1)$ \\
\hline Yes & $498(31.0)$ & $93(3.9)$ \\
\hline Hypertension & $492(30.7)$ & $520(21.7)$ \\
\hline Decreased HDL & $286(17.8)$ & $502(21.0)$ \\
\hline High TG & $354(22.0)$ & $343(14.3)$ \\
\hline Diabetes & $167(10.4)$ & $220(9.2)$ \\
\hline
\end{tabular}

Categorical data were reported as percentages and continuous data were reported as means \pm SD.

$\mathrm{BMI}$, body mass index; DBP, diastolic blood pressure; FPG, fasting plasma glucose; HDL-C, high-density lipoprotein cholesterol; 2hPG, 2-hour post-load plasma glucose; LDL-C, low-density lipoprotein cholesterol; NC, neck circumference; SBP, systolic blood pressure; TC, total cholesterol; TG, triglycerides; WC, waist circumference.

increased LDL-C was defined as LDL-C $\geq 4.14 \mathrm{mmol} / \mathrm{L}$ and decreased HDL-C was defined as HDL-C $<1.04$ $\mathrm{mmol} / \mathrm{L}^{24}$

\section{Statistical methods}

Categorical data were reported as number and percentage, while continuous data were reported as mean \pm SD. Partial correlation analysis was used to examine the correlations between $\mathrm{NC}$ and the cardiometabolic disease indexes. Logistic regression models were used to evaluate the association between $\mathrm{NC}$ and dichotomous cardiometabolic diseases. Model 1 only included NC. Model 2 was adjusted for age, sex, smoking, drinking and education. Model 3 was adjusted for BMI and the covariates in model 2. Model 4 was adjusted for WC and the covariates in model 2. Model 5 was adjusted for BMI, WC and the covariates in model 2. The optimal cut-off values and predictive abilities of $\mathrm{NC}$ were evaluated using ROC analysis, and the results were confirmed using logistic regression models to compare the associations between the $\mathrm{NC}$ categories and the cardiometabolic disease. All data were entered into a database in a double-blind manner by two different researchers, who used EpiData software (V.3.0). All statistical analyses were performed using SPSS software (V.19.0). Two-tailed pvalues were considered statistically significant at $<0.05$.

\section{Results}

Table 1 presents the participants' main characteristics. The mean age was 56.0 \pm 9.8 years (men: $56.02 \pm 10.15$ years, women: $55.95 \pm 9.53$ years). The overall average $\mathrm{NC}$ was $33.59 \pm 4.16 \mathrm{~cm}$, with average values of $35.50 \pm 4.23 \mathrm{~cm}$ for men and $32.32 \pm 3.59 \mathrm{~cm}$ for women. Table 2 shows that there were several age-adjusted correlations between $\mathrm{NC}$ and the cardiometabolic disease indexes. Among men, NC was significantly correlated with SBP $(r=0.112$, $\mathrm{p}<0.01)$, DBP $(\mathrm{r}=0.185, \mathrm{p}<0.01)$, FPG $(\mathrm{r}=0.115, \mathrm{p}<0.01)$, 2hPG $(\mathrm{r}=0.132, \mathrm{p}<0.01)$, TG $(\mathrm{r}=0.176, \mathrm{p}<0.01)$, LDL-C $(\mathrm{r}=0.107, \mathrm{p}<0.01)$, HDL-C $(\mathrm{r}=-0.087, \mathrm{p}<0.01)$, smoking $(\mathrm{r}=0.066, \mathrm{p}=0.011)$, drinking $(\mathrm{r}=0.067, \mathrm{p}=0.007)$ and physical activity $(r=0.101, p<0.01)$. However, $N C$ was not significantly correlated with TC among men $(\mathrm{r}=0.01, \mathrm{p}=0.709)$. The same significant correlations were observed among women, with the exception of the correlation between $\mathrm{NC}$ and LDL-C $(\mathrm{r}=0.034, \mathrm{p}=0.11)$.

Table 2 Partial correlations between neck circumference and the cardiometabolic disease indexes

\begin{tabular}{lccccc}
\hline & \multicolumn{2}{l}{ Men } & & \multicolumn{2}{l}{ Women } \\
\cline { 2 - 3 } \cline { 5 - 6 } Variable & $\mathbf{R}$ & P value & & R & P value \\
\hline SBP & 0.112 & $<0.01$ & & 0.149 & $<0.01$ \\
DBP & 0.185 & $<0.01$ & & 0.133 & $<0.01$ \\
FPG & 0.115 & $<0.01$ & & 0.123 & $<0.01$ \\
2hPG & 0.132 & $<0.01$ & & 0.145 & $<0.01$ \\
TG & 0.176 & $<0.01$ & & 0.177 & $<0.01$ \\
TC & 0.010 & 0.709 & & 0.022 & 0.292 \\
LDL-C & 0.107 & $<0.01$ & & 0.034 & 0.110 \\
HDL-C & -0.087 & $<0.01$ & & -0.054 & 0.010 \\
Smoking & 0.066 & 0.011 & 0.054 & 0.010 \\
Drinking & 0.067 & 0.077 & & 0.056 & 0.008 \\
\hline Physical activity & 0.101 & $<0.01$ & 0.067 & 0.001 \\
\hline
\end{tabular}

Pearson partial correlation coefficients, adjusted for age. DBP, diastolic blood pressure; FPG, fasting plasma glucose; HDL-C, high-density lipoprotein cholesterol; 2hPG, 2-hour post-load plasma glucose; LDL-C, low-density lipoprotein cholesterol; SBP, systolic blood pressure; TC, total cholesterol; TG, triglycerides. 


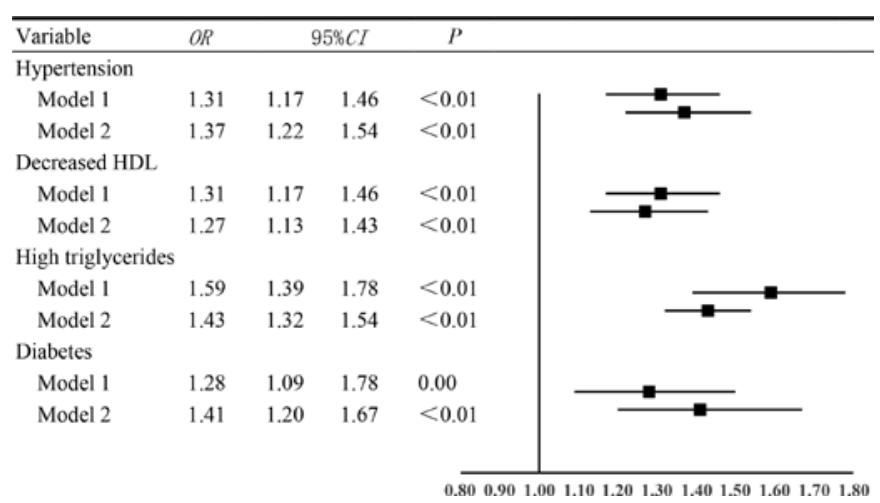

Figure 1 Neck circumference (continuous data) in relation to the risk of cardiometabolic disease in male patients. Model 1: unadjusted; model 2: adjusted for age, sex, smoking, drinking and education; NC, neck circumference (continuous data).

Multivariate logistic regression analysis was used to evaluate the associations between $\mathrm{NC}$ and cardiometabolic disease (figures 1 and 2). In the multivariate model (model 2), men with large NC values had elevated risks of hypertension (adjusted OR: 1.37, 95\% CI 1.22 to 1.54), decreased HDL levels (OR: $1.27,95 \%$ CI 1.13 to 1.43), high TG levels (OR: $1.43,95 \%$ CI 1.32 to 1.54 ) and diabetes (OR: $1.41,95 \%$ CI 120 to 1.67 ). Women with large $\mathrm{NC}$ values also had elevated risks of hypertension (OR: $1.42,95 \%$ CI 1.28 to 1.58 ), decreased HDL levels (OR: 1.12, 95\% CI 1.01 to 1.23), high TG levels (OR: 1.54, 95\% CI 1.38 to 1.73 ) and diabetes (OR: $1.37,95 \%$ CI 1.20 to 1.57$)$.

The ROC analysis results are shown in table 3. Among men, the optimal NC cut-off values were $38.10 \mathrm{~cm}$ for hypertension (area under the curve (AUC): 0.567), $32.25 \mathrm{~cm}$ for decreased HDL levels (AUC: 0.573), 36.60 $\mathrm{cm}$ for high TG levels (AUC: 0.631) and $36.60 \mathrm{~cm}$ for diabetes (AUC: 0.557). Among women, the optimal NC cut-off values were $32.35 \mathrm{~cm}$ for hypertension (AUC: 0.606), $33.40 \mathrm{~cm}$ for decreased HDL levels (AUC: 0.537),

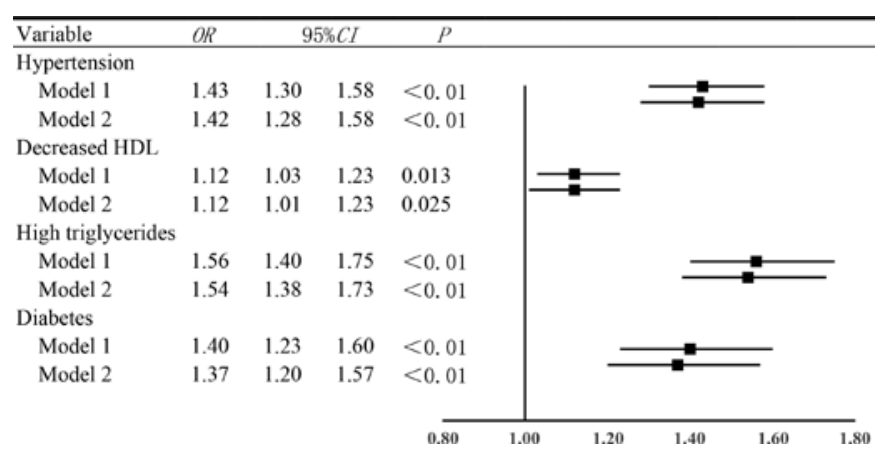

Figure 2 Neck circumference (continuous data) in relation to the risk of cardiometabolic disease in female patients. Model 1: unadjusted; model 2: adjusted for age, sex, smoking, drinking and education; NC, neck circumference (continuous data).

$32.90 \mathrm{~cm}$ for high TG levels (AUC: 0.633 ) and $33.40 \mathrm{~cm}$ for diabetes (AUC: 0.596). Moreover, we evaluated the associations between the NC categories and the risks of cardiometabolic disease according to sex (table 4). After adjusting for age, sex, smoking, drinking, education, BMI and WC, both men and women with the high values for each NC category had elevated risks of the corresponding cardiometabolic disease index, with the exceptions of hypertension and high TG levels among men. Additionally, we analysed the risk of cardiometabolic disease per 1-SD increase in NC, WC and BMI in online supplementary table $\mathrm{S} 1$. We also compared the predictive value of NC, BMI and WC for hypertension, decreased HDL, high TG and diabetes in online supplementary table S2.

\section{DISCUSSION}

The present study found that NC was associated with cardiometabolic disease, regardless of adjustment for other confounders. Our study also indicated that BMI and WC are associated with cardiometabolic diseases.

Table 3 Areas under the receiver operating characteristic by neck circumference to identify participants with cardiometabolic disease

\begin{tabular}{|c|c|c|c|c|c|c|c|c|c|}
\hline Variable & AUC & $95 \% \mathrm{Cl}$ & Cut-off point & Sensitivity & Specificity & PPV & NPV & +LR & -LR \\
\hline \multicolumn{10}{|l|}{ Men } \\
\hline Hypertension & 0.567 & 0.536 to 0.598 & 38.10 & 0.242 & 0.856 & 0.426 & 0.408 & 1.681 & 0.886 \\
\hline Decreased HDL & 0.573 & 0.543 to 0.603 & 32.25 & 0.889 & 0.238 & 0.324 & 0.839 & 1.167 & 0.466 \\
\hline High triglycerides & 0.631 & 0.599 to 0.664 & 36.6 & 0.562 & 0.655 & 0.316 & 0.841 & 1.629 & 0.669 \\
\hline Diabetes & 0.557 & 0.509 to 0.604 & 36.6 & 0.479 & 0.621 & 0.128 & 0.911 & 1.264 & 0.839 \\
\hline \multicolumn{10}{|l|}{ Women } \\
\hline Hypertension & 0.606 & 0.578 to 0.634 & 32.35 & 0.552 & 0.614 & 0.148 & 0.832 & 1.430 & 0.730 \\
\hline Decreased HDL & 0.537 & 0.511 to 0.564 & 33.40 & 0.313 & 0.748 & 0.285 & 0.521 & 1.242 & 0.918 \\
\hline High triglycerides & 0.633 & 0.602 to 0.664 & 32.90 & 0.586 & 0.614 & 0.201 & 0.899 & 1.518 & 0.674 \\
\hline Diabetes & 0.596 & 0.556 to 0.636 & 33.40 & 0.4 & 0.747 & 0.138 & 0.925 & 1.580 & 0.803 \\
\hline
\end{tabular}

AUC, area under the curve; +LR, positive likelihood ratio; -LR, negative likelihood ratio; NPV, negative predictive value; PPV, positive predictive value; ROC, receiver operating characteristic. 
Table 4 Association of neck circumference (categorical data) with the risk of cardiometabolic disease

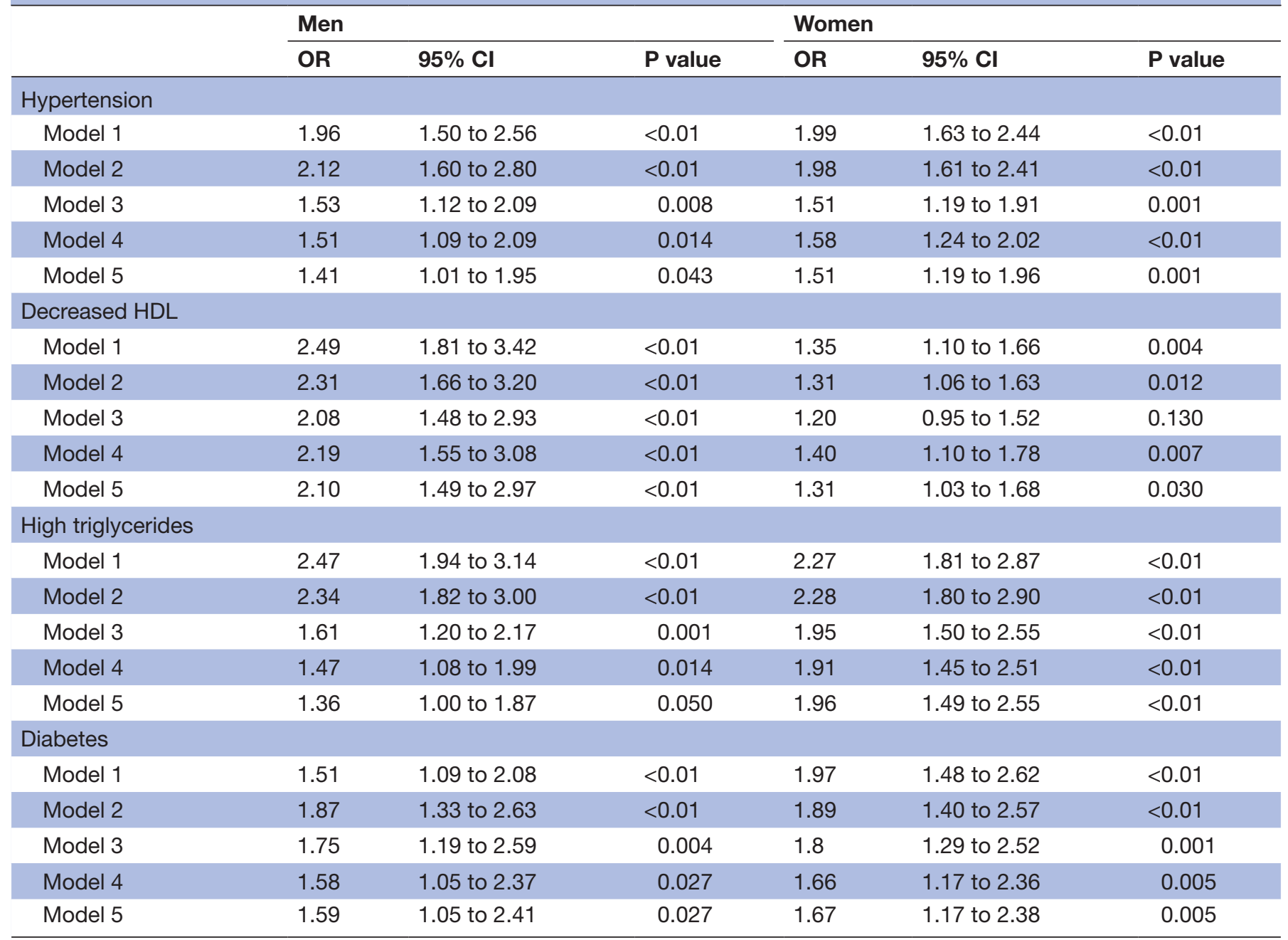

Model 1: unadjusted; model 2: adjusted for age, sex, smoking, drinking and education; model 3: adjusted for age, sex, smoking, drinking, education and BMI; model 4: adjusted for age, sex, smoking, drinking, education and WC; model 5: adjusted for age, sex, smoking, drinking, education, BMI and WC.

For hypertension, neck circumference $<38.10 \mathrm{~cm}$ was the reference in men and neck circumference $<32.35 \mathrm{~cm}$ was the reference in women. For decreased HDL, neck circumference $<32.25 \mathrm{~cm}$ was the reference in men and neck circumference $<33.4 \mathrm{~cm}$ was the reference in women. For high triglycerides, neck circumference $<36.6 \mathrm{~cm}$ was the reference in men and neck circumference $<32.9 \mathrm{~cm}$ was the reference in women. For diabetes, neck circumference $<36.6 \mathrm{~cm}$ was the reference in men and neck circumference $<33.4 \mathrm{~cm}$ was the reference in women.

BMI, body mass index; HDL, high-density lipoprotein; WC, waist circumference.

Although BMI is widely used to define overweight and obesity, the criteria using BMI to determine obesity varies across different populations, which makes it unable to directly measure body fat or implicate the distribution of fat. ${ }^{2526} \mathrm{WC}$ is the most commonly used anthropometric parameter for evaluating abdominal adiposity, but either the structure of the abdominal wall or abdominal organs and cavity can be affected through the variations of WC in time and conditions. Moreover, it may not be applicable for study with large sample population, especially in cold weather people would wear heavy clothes. ${ }^{27}$ Conversely, $\mathrm{NC}$, as a simple, time-saving and stable anthropometric measurement, was a phenotype of upper body fat depot and it may also affect the cardiometabolic system. ${ }^{28}$ Furthermore, the present study established several NC cut-off values for identifying cardiometabolic disease in this population. Similar results have been observed in previous studies. For example, Preis $e t$ al found that, in the Framingham Heart Study of 2732 subjects, NC was related to hypertension, low HDL levels and diabetes. ${ }^{15}$ Selim $e t$ al also suggested that NC could be used to identify children with an elevated risk of cardiometabolic disease.$^{29}$ Furthermore, Cho et al evaluated 3521 middleaged Korean individuals and reported that NC was positively correlated with diabetes. ${ }^{30}$ Lee and colleagues found that $\mathrm{NC}$ was associated with hypertension. ${ }^{31} \mathrm{He}$ et al shown that NC is a tool for screening gestational diabetes mellitus. ${ }^{32}$ Those results, combined with our findings, shown that there were positive associations between $\mathrm{NC}$ and risks of hypertension, decreased HDL levels, high TG levels and diabetes. 
Several potential mechanisms have been proposed to explain the relationships between NC and cardiometabolic disease. For example, the lipolytic activity of upper body fat may explain the association of $\mathrm{NC}$ with hypertension. ${ }^{33}$ In addition, obesity and elevated plasma levels of free fatty acids are associated with insulin resistance and increased very LDL production. ${ }^{13} 3435$ Increased levels of free fatty acids are also correlated with markers of oxidative stress and vascular injury, and are associated with the development of hypertension. ${ }^{36}{ }^{37}$ Furthermore, high $\mathrm{NC}$ values are a significant predictor of obstructive sleep apnea syndrome, ${ }^{38}$ which has been associated with poor glycaemic control. This is because, even at the earliest stages of glucose intolerance, intermittent hypoxaemia and sleep fragmentation increase the risk of insulin resistance.

The present study revealed that $\mathrm{NC}$ was related to hypertension and high TG levels among men and women, although these relationships disappeared among men after adjusting for BMI and WC. This result does not agree with the findings from previous studies, ${ }^{18} 19$ and this discrepancy may be related to differences in genetic background, dietary habits and the effects of other confounding factors. Moreover, these discrepancies could be related to the use of studies with cross-sectional designs, and prospective population-based studies are needed to address this issue.

In addition, the logistic regression models were used to evaluate the associations of the $\mathrm{NC}$ categories with the cardiometabolic disease indexes, which confirmed elevated risks of each index for individuals with $\mathrm{NC}$ values that exceeded the corresponding cut-off values. Therefore, it appears that NC is a tool for identifying cardiometabolic diseases, which provides evidences for future researches, but more studies are needed to verify the accuracy and effectiveness of $\mathrm{NC}$ as the predictor of cardiometabolic diseases. Moreover, to the best of our knowledge, this is the first study to establish the optimal NC cut-off values for predicting decreased HDL levels, high TG levels, and diabetes in a Chinese population, as previous studies have focused on detecting hypertension using NC. For example, Assyov et al reported that hypertension was predicted using NC cut-off values of $\geq 38 \mathrm{~cm}$ among Caucasian men and $\geq 35 \mathrm{~cm}$ among Caucasian women. ${ }^{39}$ A recent study of 2631 individuals in northeastern China also revealed that hypertension was predicted using NC cut-off values of $>35.75 \mathrm{~cm}$ among men and $>32.75$ $\mathrm{cm}$ among women. ${ }^{19}$ Subsequent studies conducted in Korean population further confirmed the finding of Zhou et al that NC was a valuable index for identifying hypertension among Chinese adults. ${ }^{32}$ Thus, there appear to be population-specific variations in the optimal NC cut-off values, which were $>38.10 \mathrm{~cm}$ among men and $>32.25 \mathrm{~cm}$ among women in the present study. These discrepancies could be related to population-based differences in body size and composition. ${ }^{36}$ Therefore, we suggest that future studies are needed to determine population-specific cutoff values for using NC to predict cardiometabolic disease.

\section{CONCLUSION}

The present study's results, combined with the findings of previous studies, indicate that $\mathrm{NC}$ is associated with cardiometabolic disease among Chinese adults. Thus, we recommend incorporating NC evaluations into clinical assessments. However, longitudinal studies are needed to validate the associations that we observed, and to establish population-specific cut-off values for using NC to predict cardiometabolic disease risk.

\section{Author affiliations}

${ }^{1}$ Department of Social Medicine and Health Management of Public Health, Tongji Medical College, Huazhong University of Science and Technology, Wuhan, China ${ }^{2}$ School of Nursing, Tongji Medical College, Huazhong University of Science and Technology, Wuhan, China

${ }^{3}$ Department of Neurology, Taihe Hospital, Hubei University of Medicine, Shiyan, China

${ }^{4}$ Deparment of Chronic disease management, Bao'an Central Hospital of Shenzhen, Shenzhen, China

${ }^{5}$ Public Health, Hainan Medical University, Haikou, China

${ }^{6}$ Key Laboratory of Emergency and Trauma of Ministry of Education, Hainan Medical University, Haikou, China

Acknowledgements We thank all staff members and all participants involved in this study.

Contributors WF, YG and ZL conceived and designed the study. WF, XY, JM, SZ, LZ, $S C, W L, Y G$ and SY participated in the acquisition of data. WF analysed the data. XY and $L Z$ gave advice on methodology. WF drafted the manuscript, and XY, YG and ZL revised the manuscript. All authors read and approved the final manuscript. ZL is the guarantor of this work and had full access to all the data in the study and take responsibility for its integrity and the accuracy of the data analysis.

Funding This study was supported by the Innovation Committee of Shenzhen Science and Technology, 'Demonstration Application of Cardiovascular and Cerebrovascular Disease Prevention and Control Based on Functional Community'(KJYY20170413162318686), and the FundamentalResearch Funds for the Central Universities, Huazhong University of Science and Technology, China. (2016YXMS215).

Competing interests None declared.

Patient consent for publication Not required.

Ethics approval Written informed consent was obtained from all individuals, and the study protocol was approved by the Ethics Committee of Tongji Medical College, Huazhong University of Science and Technology, Wuhan, China.

Provenance and peer review Not commissioned; externally peer reviewed. Data availability statement № data are available.

Open access This is an open access article distributed in accordance with the Creative Commons Attribution Non Commercial (CC BY-NC 4.0) license, which permits others to distribute, remix, adapt, build upon this work non-commercially, and license their derivative works on different terms, provided the original work is properly cited, appropriate credit is given, any changes made indicated, and the use is non-commercial. See: http://creativecommons.org/licenses/by-nc/4.0/.

\section{REFERENCES}

1 Stefan N, Häring H-U, Hu FB, et al. Divergent associations of height with cardiometabolic disease and cancer: epidemiology, pathophysiology, and global implications. Lancet Diabetes Endocrinol 2016;4:457-67.

$2 \mathrm{Kim}$ TN, Choi KM. The implications of sarcopenia and sarcopenic obesity on cardiometabolic disease. J Cell Biochem 2015;116:1171-8.

3 Whitlock G, Lewington S, Sherliker P, et al. Body-mass index and cause-specific mortality in 900000 adults: collaborative analyses of 57 prospective studies. Lancet 2009;373:1083-96.

4 Gordon-Larsen P, Wang H, Popkin BM. Overweight dynamics in Chinese children and adults. Obes Rev 2014;15(Suppl 1):37-48. 
5 Rosolová H, Pelikánová T, Motovská Z. ESC guidelines on diabetes, pre-diabetes, and cardiovascular diseases developed in collaboration with EASD. Summary of the document prepared by the Czech Society of cardiology. Cor Vasa 2014;56:e190-205.

6 Fox CS, Golden SH, Anderson C, et al. Update on prevention of cardiovascular disease in adults with type 2 diabetes mellitus in light of recent evidence: a scientific statement from the American heart association and the American diabetes association. Diabetes Care 2015;38:1777-803.

7 Kawarazaki W, Fujita T. The role of aldosterone in obesity-related hypertension. Am J Hypertens 2016;29:415-23.

8 Gallagher EJ, LeRoith D, Obesity LD. Obesity and diabetes: the increased risk of cancer and cancer-related mortality. Physiol Rev 2015;95:727-48.

9 Wing RR, Jeffery RW, Burton LR, et al. Change in waist-hip ratio with weight loss and its association with change in cardiovascular risk factors. Am J Clin Nutr 1992;55:1086-92.

10 Schunkert H, Markus MRP, Stritzke J. Waist circumference and cardiovascular risk. New York: Springer, 2012.

11 Fox CS, Massaro JM, Hoffmann U, et al. Abdominal visceral and subcutaneous adipose tissue compartments: association with metabolic risk factors in the Framingham heart study. Circulation 2007:116:39-48.

12 Huxley R, James WPT, Barzi F, et al. Ethnic comparisons of the cross-sectional relationships between measures of body size with diabetes and hypertension. Obes Rev 2008;9(Suppl 1):53-61.

13 Lee CMY, Huxley RR, Wildman RP, et al. Indices of abdominal obesity are better discriminators of cardiovascular risk factors than BMI: a meta-analysis. J Clin Epidemiol 2008;61:646-53.

14 Freedman DS, Rimm AA. The relation of body fat distribution, as assessed by six girth measurements, to diabetes mellitus in women. Am J Public Health 1989;79:715-20.

15 Preis SR, Massaro JM, Hoffmann U, et al. Neck circumference as a novel measure of cardiometabolic risk: the Framingham heart study. $J$ Clin Endocrinol Metab 2010;95:3701-10.

16 Ben-Noun L, Laor A. Relationship of neck circumference to cardiovascular risk factors. Obes Res 2003:11:226-31.

17 Preis SR, Pencina MJ, D'Agostino RB, et al. Neck circumference and the development of cardiovascular disease risk factors in the Framingham heart study. Diabetes Care 2013;36:e3.

18 Zhou J-ya, Ge H, Zhu M-fan, et al. Neck circumference as an independent predictive contributor to cardio-metabolic syndrome. Cardiovasc Diabetol 2013;12:76-7.

19 Fan S, Yang B, Zhi X, et al. Neck circumference associated with arterial blood pressures and hypertension: a cross-sectional community-based study in northern Han Chinese. Sci Rep 2017;7:2620.

20 Luo Y, Ma X, Shen Y, et al. Neck circumference as an effective measure for identifying cardio-metabolic syndrome: a comparison with waist circumference. Endocrine 2017:55:822-30.

21 Khalangot M, Gurianov V, Okhrimenko N, et al. Neck circumference as a risk factor of screen-detected diabetes mellitus: communitybased study. Diabetol Metab Syndr 2016;8

22 Yan Q, Sun D, Li X, et al. Neck circumference is a valuable tool for identifying metabolic syndrome and obesity in Chinese elder subjects: a community-based study. Diabetes Metab Res Rev 2014;30:69-76.
23 Daskalopoulou SS, Rabi DM, Zarnke KB, et al. The 2015 Canadian hypertension education program recommendations for blood pressure measurement, diagnosis, assessment of risk, prevention, and treatment of hypertension. Can J Cardiol 2015;31:549-68.

24 Chinese adult dyslipidemia prevention and control guidelines for the development of joint committees. Chinese guidelines on prevention and treatment of dyslipidemia in adults. J Cardiovasc Dis Res 2007;35:390-419.

25 Sturm R. Increases in morbid obesity in the USA: 2000-2005. Public Health 2007:121:492-6.

26 Kanazawa M, Yoshiike N, Osaka T, et al. Criteria and classification of obesity in Japan and Asia-Oceania. World Rev Nutr Diet 2005;94:1-12.

27 Zhou B-F, Cooperative Meta-Analysis Group of the Working Group on Obesity in China. Predictive values of body mass index and waist circumference for risk factors of certain related diseases in Chinese adults-study on optimal cut-off points of body mass index and waist circumference in Chinese adults. Biomed Environ Sci 2002;15:83-96

28 Stabe C, Vasques ACJ, Lima MMO, et al. Neck circumference as a simple tool for identifying the metabolic syndrome and insulin resistance: results from the Brazilian metabolic syndrome study. Clin Endocrinol (Oxf) 2013;78:874-81.

29 Kurtoglu S, Hatipoglu N, Mazicioglu MM, et al. Neck circumference as a novel parameter to determine metabolic risk factors in obese children. Eur J Clin Invest 2012;42:623-30.

$30 \mathrm{Cho} \mathrm{NH}$, Oh TJ, Kim KM, et al. Neck circumference and incidence of diabetes mellitus over 10 years in the Korean genome and epidemiology study (KoGES). Sci Rep 2015;5:18565.

31 Lee BJ, Kim JY, Yeol KJ. A comparison of the predictive power of anthropometric indices for hypertension and hypotension risk. PLOS One 2014;9:e84897.

$32 \mathrm{He} \mathrm{F}, \mathrm{He} \mathrm{H}$, Liu W, et al. Neck circumference might predict gestational diabetes mellitus in Han Chinese women: a nested casecontrol study. J Diabetes Investig 2017;8:168-73.

33 Griffin ME, Marcucci MJ, Cline GW, et al. Free fatty acid-induced insulin resistance is associated with activation of protein kinase $\mathrm{C}$ theta and alterations in the insulin signaling cascade. Diabetes 1999;48:1270-4.

34 Boden G, Shulman Gl. Free fatty acids in obesity and type 2 diabetes: defining their role in the development of insulin resistance and beta-cell dysfunction. Eur J Clin Invest 2002;32(Suppl 3):14-23.

35 Keaney JF, Larson MG, Vasan RS, et al. Obesity and systemic oxidative stress: clinical correlates of oxidative stress in the Framingham study. Arterioscler Thromb Vasc Biol 2003;23:434.

36 Kelley DE, Mokan M, Simoneau JA, et al. Interaction between glucose and free fatty acid metabolism in human skeletal muscle. $J$ Clin Invest 1993:92:91-8.

37 Kissebah AH, Alfarsi S, Adams PW, et al. Role of insulin resistance in adipose tissue and liver in the pathogenesis of endogenous hypertriglyceridaemia in man. Diabetologia 1976;12:563-71.

38 Young T, Shahar E, Nieto FJ, et al. Predictors of sleep-disordered breathing in community-dwelling adults: the sleep heart health study. Arch Intern Med 2002;162:893.

39 Zimmet P, Magliano D, Matsuzawa Y, et al. The metabolic syndrome: a global public health problem and a new definition. $J$ Atheroscler Thromb 2005;12:295-300. 